ranged from a replica of Marconi's original transmitter as used in 1897 to the marine type of rotating radar aerial with P.P.I. display which is being fitted to merchant ships to-day. Special attention was also given to the modern applications of radio waves, including high-speed communication and printing equipment, direction-finding apparatus, and mobile telegraph and telephone equipment for police and other purposes. In view of the present widespread use of radio waves for communication, broadcasting, television, navigational aids, surgical and industrial purposes, it is interesting to have this reminder that the whole of the technique in these fields has been developed during the past fifty years.

\section{Amalgamation of the Institutions of Mechanical Engineers and Automobile Engineers}

AN important and heartening announcement is that of the amalgamation of the Institution of Mechanical Engineers and of the Institution of Automobile Engineers, which took place on April 13. During the past fifty years and more, the individual energies of engineers have been dissipated and their corporate authority has been lessened by the multiplicity of engineering institutions which grew up to satisfy the needs of specialist branches of the profession. Though many of these younger institutions have done excellent work in furthering the development of particular sections of engineering, which it was felt at the time of their foundation were neglected by the senior institutions, there is no doubt that the engineering profession has been split by conflicting allegiances, and that it has been more difficult for engineers to speak with one voice on important issues. The Institution of Mechanical Engineers was founded in 1847 , so that the amalgamation occurs most happily in the year that the Institution celebrates its centenary. The Institution of Automobile Engineers is forty-one years old.

Under the terms of the agreement to amalgamate, the Institution of Automobile Engineers will surrender its charter and dissolve the Institution. Its corporate members will become corporate members of the Institution of Mechanical Engineers, being placed as the first members on the register of a newly formed Automobile Division. Whatever the advantages of the welding together of the combined membership-and they are great -it has clearly been made possible only by the generous and broad view taken, in the first place, by those holding office in the Institutions. The amalgamation augurs well for the future of mechanical engineering, and it is to be hoped that other institutions will not be slow to follow the example.

\section{Jubilee of the Electron}

AprIL 30 marked the fiftieth anniversary of the announcement by J. J. Thomson, at an evening discourse at the Royal Institution, of the existence of the electron, and the first approximate estimate of its mass. Cathode rays had been extensively studied in many laboratories for the previous fifteen or twenty years, and their peculiar properties had been widely discussed. It was Thomson's genius which enabled him to unravel the confusing and almost contradictory clues which the experiments afforded as to the nature of the phenomenon, to grasp what was important and what was secondary in the evidence, and to make the final experiment which demonstrated beyond all reasonable doubt that the cathode rays consisted of negatively charged particles, all alike, and all much smaller than the smallest particle hitherto known to science, the atom of hydrogen. The Institute of Physics and the Physical Society, in collaboration with the Institution of Electrical Engineers, is arranging to mark this jubilee by a series of lectures and other functions in London on September 25-26 next; an exhibition demonstrating the great influence this discovery in pure physics has had on the life of the community will be opened at the Science Museum, London, on September 26 and will remain open for about three months.

\section{Heredity}

THE importance of an international forum of publication in science is not likely to be underestimated by readers of Nature.' In many branches of science the responsibility was undertaken before the War by journals published in Germany and, to a less extent, in Italy and Japan. Their sudden removal by war was not so seriously felt at the time, owing to the temporary reduction of fundamental research, but it has now raised a serious problem. The position of genetics in this regard is a special one. This science is not only rapidly advancing but it is also rapidly broadening its scope. Indeed it is beginning to cover every aspect of biology and every form of life. It is beginning to weave the threads of many different sciences and techniques into a single pattern. Darwinism and biometry, Mendelism and cytology are being joined together, and the needs of medicine and agriculture are being met by the estab. lishment of a single fundamental discipline. But the work that is necessary to accomplish this task is scattered over the whole world and is developing different characters in different countries.

In these circumstances an explicitly international journal of genetics is bound to serve a useful purpose. Dr. C. D. Darlington and Prof. R. A. Fisher are founding such a journal in collaboration with a group of distinguished foreign geneticists. It will be known as Heredity and will be published by Messrs. Oliver and Boyd. The articles promised for the first volume (of which Part 1 is now due to appear) include contributions from a dozen different countries. They cover, if not the whole range of genetics, at least a large part of it. Of outstanding interest perhaps is a bibliography of genetics articles published in Germany and Italy during the War and a summary of British work for the same period. The development of this journal will be watched with keen interest throughout the scientific world.

\section{Whitworth Scholarship Regulations}

NEw regulations for the Whitworth Scholarships which the Minister of Education will offer for competition in 1948 have been published (H.M. Stationery Office. 3d. net). The following awards will be avail. able: two Whitworth Senior Scholarships, tenable for two years, valued at $£ 325$ each ; five Whitworth Scholarships, tenable for three years, minimum value $£ 200$ each; ten prizes valued at $£ 20$ each, to unsuccessful competitors for Whitworth scholarships whose work deserves recognition, the money to be spent in the furtherance of the competitor's engineering education. The conditions governing the Whitworth Scholarships have now been altered in two main respects. Candidates must have com. pleted twenty-four months of works training instead. 